\title{
TRIPLE T: TOURISM, TRANSMODERNITY AND TRANSFORMATIVE LEARNING
}

\begin{abstract}
This paper brings together 'triple $T$ ' of tourism, transmodernity and transformative learning by exposing critical questions of (tourism) futures and the sense of direction where are we going as a single humanity. In the current context of overwhelming crisis at all levels - environmentally, socially, economically, politically and culturally, there is an increasing evidence that we cannot continue with 'business as usual'. Hence, natural and social science, economists, political activists, writers, spiritual leaders and successful social entrepreneurs argue that humanity needs (and is actually go-
\end{abstract}

\section{Introduction}

When we speak about tourism education today, we need to ask ourselves for what kind of (tourism) futures we educate our students? In asking so, the most immediate point of departure is the current alarming state of the world system affairs and its unsustainable practices. When one looks at the facts and scientific warnings the most natural question needs to be imposed: where are we going and what are we doing as a single humanity? Let the facts speak for themselves.

The structure of the world's ecosystems changed more rapidly in the second half of the 20th century than at any time in recorded human history (Millennium Ecosystem Assessment, 2005). The world population is growing rapidly, putting more pressure ing through) a major global mind change and a paradigm shift in the $21^{\text {st }}$ century which is often described as the shift towards transmodernity. In exposing so, the paper then connects tourism and transformative learning asa potential catalyst to change the world for the better.

Acknowledgment: This paper is based on the project 'Trans-Tourism: An integrated approach for the study of transformative role of tourism in the $21^{\text {st }}$ century', that has been fully supported by the Croatian Science Foundation, under the project no. 6164.

on the earth's recourses, there are many oil spilling disasters, we produce huge amounts of waste and also plastic, causing, for example, 'plastic-soup' in the oceans, there is loss of habitat and thanks to our economical 'development' (a word suggesting it is developing in the right direction) $\mathrm{CO} 2$ levels are increasing (Millennium Ecosystem Assessment, 2005), causing global climate change. When all other life-threatening practices are added in terms of pesticides, pops and other poisons in our waters and food chains, acidification, etc., it is not surprising that some prestigious scientists are warning us that the face of humanity and Gaia (Greek name for the Earth) is on the way to get vanished (Lovelock, 2009; 2014).

In fact, in 2007 leading scientists announced that industrial humanity has pushed the earth's biosphere into a new 
human driven geological era known as the Anthropocene (Crutzen, Steffen, and McNeil, 2007). In the same year, the reality of climate change decisively broke into global mainstream consciousness as UN secretary general Ban Ki Moon had stated: 'This year through the IPCC, the world's scientists have spoken, clearly and in one voice. Not some scientists. Not leading scientists. But the world's scientists - united' (Scott, 2008). The Intergovernmental Panel on Climate Change (IPCC) Fourth Assessment Report (2007) confirmed this by announcing that there is over $90 \%$ probability that the burning of fossil fuel emissions has caused warming since the 1950s. The global consensus agreed upon at the Copenhagen Accord in 2010 is that global warming should not increase beyond $2^{\circ}$ Celsius from preindustrial levels (UNFCC, 2009). However, as climate scientist Kevin Anderson warns - if we do not make drastic cuts in emissions we will be seeing a $4^{\circ}$ Celsius rise this century, and this potential future is incompatible with any reasonable characterisation of an organised, equitable and civilised global community' (Anderson, 2012). Furthermore, in the last two centuries the dramatic changes of land use has transformed the biosphere, with the clearing or the conversion of $70 \%$ of the grassland, $50 \%$ of the savannah, $45 \%$ of the temperate deciduous forest, and $27 \%$ of the tropical forest biome for agriculture (FAO, 2011).

Economically and socially, the world is not doing any better either. Detrimental impacts on the body of Earth inevitably reflect in the state of our social and individual well-being. The 2009 economic collapse of the Wall Street continues to affect the world economy while the gap between the rich and the poor is getting wider. The latest Credit Suisse report (2014) shows that top $1 \%$ of global population 'owns half of global wealth' - (http://www.bbc.com/news/business-29641109). Yet, longitudinal studies in rich countries of the West show that increas- ing material wealth does not increase happiness either. This growing dissatisfaction with our dominant socio-economic model is clearly illustrated in the fact that the consumption of antidepressants is continuously on the rise in rich countries (OECD, 2013). Consequently, it appears that the current unsustainable, materialist paradigm increasingly pressures people (worldwide, although predominantly in the West) to search for a new worldview of higher values and more responsible, meaningful lives. The paper briefly describes this paradigm shift, followed by discussion on links between tourism and transformative learning.

\section{'Silent revolution' and the shift towards transmodernity}

Natural and social science, economists, political activists, writers, spiritual leaders and many successful social entrepreneurs argue that humanity needs (and is actually going through) a major global mind change and a paradigm shift in the $21^{\text {st }}$ century. To describe this emerging socio-cultural, economic, political and philosophical shift of consciousness, values, worldviews, and paradigms, different authors from different disciplines use a variety of terms, such as transmodernity paradigm; transmodern philosophy of political liberation; integral culture; circularity paradigm;reflective/living-systems paradigm; partnership model of caring economics; relational global consciousness and biosphere politics, to name a few.Yet, regardless of different terminology, all authors point in the same direction - the planetary vision in which humans are beginning to realize that we are all (including plants and animals) connected into one system, which makes us all interdependent, vulnerable and responsible for the Earth as an indivisible living community.

While it goes beyond the scope of this paper to discuss the shift in full detail some 
of the key tenets will be given here (for a full theoretical overview see Ateljevic, 2013). The shift is associated around phenomenon of the so-called 'silent revolution' led by the growing number of so-called 'Cultural Creatives' (Ray and Anderson, 2000; Ghisi, 2008). The concept of the silent revolution of cultural creatives comes from the historian Arnold Toynbee who analysed the rise and fall of 23 civilisations in world history and who claims that when a cultural shift occurs, usually 5\% of 'creative marginals' are preparing the shift in silence. This concept has been borrowed by sociologist Paul H. Ray and psychologist Sherry Ruth Anderson who have applied it to their market cluster research of politics in America. Drawing upon 13 years of survey research studies on over 100,000 Americans, plus over 100 focus groups and dozens of in-depth interviews they have discovered that around $24 \%$ of Americans are departing from traditional or modern cultures to weave new ways of living. They describe this new subculture as the transmodern cultural creatives, who care about ecology and saving the planet, about relationships, peace, social justice, self actualization, spirituality and self-expression. They are both inner-directed and socially concerned. They are activists, volunteers and contributors to good causes - more so than other Americans. Amongst many interesting behavioural indicators, they are those who read and listen to the radio the most, and watch television the least. They reflect on themselves, actively travel and are looking for a spiritual dimension in life that goes beyond religious dogmas. In everyday life they search for the harmony of the body, mind and spirit; hence their travels often consist of spiritual and educational trips (e.g. retreats and events focused on spirituality and inner search, well-being, alternative medicine).Interestingly, 66\% in this group are women.

The evidence goes beyond the North American continent, however. The Statistics Office of the European Commission (Euro- stat) used a similar method to the American study and confirmed a similar trend of approximately $20 \%$ of the European population exhibiting a similar set of values (Ghisi, 2008). In parallel, the well-known World Values Survey (running from 1981 to date) which consists of nationally representative surveys conducted in almost 100 countries (that contain almost 90 percent of the world's population), found that a growing proportion of the population in both rich and poor countries spend time thinking about the meaning and purpose of life (Inglehart and Norris, 2004).

The shift of the paradigm has been particularly accelerated by the latest recession that seems to be serving as a key tipping point. Many popular writings and market research agencies confirm the trend. For example, Richard Florida in his book 'The Great Reset' (2010) speaks about how new ways of living and working drive post-crash prosperity. A White Paper 'A Darwinian Gale' (2010) from the Futures Company has announced the current shift towards the 'new era of consequences' with the value found in responsibility as opposed to the $20^{\text {th }}$ century 'era of indulgence' when the values were based in trading and consuming. Whilst $18^{\text {th }}$ and $19^{\text {th }}$ century were characterised as the 'era of readiness' when value was found in new frontiers.

Similarly, Euro RSCG Worldwide* (2010), a major global study that included an in-depth survey of 5,700 adults in seven countries including Brazil, China, France, Japan, the Netherlands, the United Kingdom, and the United States has shown that people in mature markets have grown tired of the constant push to accumulate more. They claim that even well before the recession, we were seeing signs of discontent being played out in positive ways. Once-fringe movements such as organic foods and recycling are becoming mainstream in mature markets, part of a growing consciousness about the impact our personal consump- 
tion choices are having on our bodies, other people, and the planet we share. Then along came the global downturn - a.k.a. the "Great Recession" - giving people an opportunity or necessity to stop and think, to consider and reassess their lives and lifestyle choices. Across the markets surveyed, people are fed up with a culture built on trips to the mall and hours spent parked in front of televisions and computer screens. Seven in ten global respondents $(69 \%)$ worry that society has become too shallow and focused on things that don't really matter. In the U.S., France, and the U.K., that figure rises to $79 \%, 77 \%$, and $75 \%$, respectively. Six in ten $(60 \%)$ believe society has grown intellectually lazy, while nearly seven in ten (67\%) believe we have grown physically lazy. In both cases, the percentages are the highest in the U.S. and U.K. Saturated by meaningless hyper consumerism, 'new consumers' still want more, but they are defining that differently. Not more mountains of consumer goods but, rather, more meaning, more deeply felt connections, more substance and a greater sense of purpose.

In the parallel line, an Ogilvy and Mather (2011) market study speaks about the emerging post-recession consumer consciousness in which, 75\% of those surveyed said that they would rather get out of the 'rat race' than climb the corporate ladder - and instead, $76 \%$ said they would rather spend more time with family than make more money. In its report 'Eyes wide open, wallet half shut' the agency identifies 'awake, alert and aware' conscious consumers across all ages and genders. Advertisers have already captured them as the market labelled LOHAS - conscious consumers with lifestyle of health and sustainability (see http://www. lohas.com/).

\section{Transformative tourism}

It is in this context, that we see the increasing trend of the growing need for conscious and transformative holidays in which travel appears to provide the means to change both - one's own life(style) as well as the impact one makes on places of visit. Academic and industry based research increasingly confirms this trend, albeit using different terms to communicate the shift towards the new travelling mindset. Some frame it as the transmodern tourism of the future; while others call it transformative tourism, while renowned destination management consultant, practitioner and change agent, Anna Pollock calls it conscious travel (http://conscious.travel/theconscioustraveller/).

Yet, regardless of the terminology employed, all research points in the same direction that also goes beyond the recognition of responsible tourism that has been widely promoted by the industry and UNWTO. For example, through the 2012 campaign 'One Billion Tourists: One Billion Opportunities', tourists are called upon to make their actions count in terms of caring for places and communities they visit (i.e. saving energy, respecting local culture, buying locally). Transformative/conscious travellers are recognised to be going further by using travel to re-invent themselves and the world. They travel in order to volunteer and make a difference; they value what's slow, small and simple and aim for self-reliance; they are connected and communicative; they seek meaningful experiences that help them to develop personally and collectively. In sum, they use travel to reflect upon their lives and get the courage to make crucial life changes upon their return back home, not only in terms of their lifestyle but also the type of work they do. Many various types of tourism have been identified that allow for developing new experiences and transforming one's personality and world-view, such as edu- 
cational, volunteer, survival, communitybased, eco, farm, extreme sports, backpacking, cultural, wellness, religious, spiritual and yoga tourism (Reisinger, 2013).

Yet, limited studies on transformative tourism show that it is not sufficient to provide 'alternative and special interest tourism' experiences only. The seismic changes in consumers' lifestyles, values and consumption patterns described above must be met by an equally seismic shift in the firms producing goods, services and experiences for the 'silent revolution' to come to fruition. The free-market capitalism that has driven business activity for centuries is now itself under question. Some would say it is broken, and different norms and drivers of business activity are needed. In Naomi Klein's (2014) book 'This Changes Everything: Capitalism versus the Climate' she addresses the urgency of transforming the broken economic system while also addressing climate change. She eloquently points to the need to drop our addiction to free-market ideologies, put an end to greed and corporate power, restructure local economies and strengthen our democracies.

This requires tourism firms to re-examine how they fit into the emerging society described above and to reflect on a new raison d'etre - one which addresses the needs of the planet and the fundamental changes affecting tourists' consumption patterns and lifestyles. The common wisdom is that the pure profit maximization goal must now stand side-by-side with goals for societal wellbeing. Otto Sharmer describes this shift as moving from ego-centricbehaviour (maximizing self-interest) to eco-centric behaviour (contributing to the social, cultural and environmental eco-systems within which the firm operates). Many business gurus (Porter and Kramer 2011, Senge et al. 2004, Sharmer and Kaufer, 2013) endorse this shared value approach to corporate activity and call for firms to wake up to their impact on the eco-systems in which they operate. This is more urgent now than it ever has been. Without such a shift, we will not '...cross through the gate to an economy that operates more consciously, inclusively, and collectively...'(Sharmer and Kaufer, 2013, p. 108). Greed, corporate power and corruption have no place in the new economy. Instead collaboration, sharing, and common values characterize economic behaviour. All avenues of business activity are undergoing this disruption, and the travel industry is not being spared.

Reflectively, an inevitable and critical question needs to posed: how can we do that when we speak about transformation of the worldviews and lifestyles around the world. The key departure point can be found in the field of transformation learning theory where the most prolific body of literature on transformation and specifically transformation in tourism is placed.

\section{Transformative learning and tourism}

According to Mezirow (1996, 2012), the founder of the transformative learning theory, there are several dimensions of transformation: 1) psychological - relating to deeper understanding of self; 2) convictional - relating to beliefs and entire ideologies; and 3) behavioural transformation when specific behaviours and lifestyle of persons, their families, communities and entire societies changes. Similarly, O'Sullivan (2012) who applies the concept of transformational learning to foster a planetary world-view, argues that transformation involves a profound structural shift in way we think, feel and act, defining transformational learning as:'a shift of consciousness that dramatically alters our way of being in the world'(O'Sullivan, 2012, p. 164). While it goes beyond the scope of this paper to discuss the rich literature on transformative learning, it appears then that one of the key features of the transformational 
process is some kind of critical event when one is faced with the new and/or unexpected. Indeed, it is precisely what Lyon (2002) finds to be common to transformational learning and cross-cultural studies - an unexpected event, experience or phenomenon with a profound impact on the individual. In cross-cultural studies this is referred to as a culture shock, while it is known in transformational studies as a disorienting dilemma. Also, some refer to the turning point as a point of enough confusion and disorientation to prompt a perspective change (Alhadeff-Jones, 2012) or a cathartic experience (McIntosh and Zahra, 2007). Faced with disorienting dilemma people are forced into self-examination and thereby questioning their own assumptions and beliefs.

The preceding discussion about transformation based on transformation learning theory has set a stage for diving into the transformational power of tourism. The general claim that the initial change which leads to transformation is triggered by an encounter with the new and unexpected giving rise to a disorienting dilemma which then makes the habitual ways of thinking and behaving to be challenged, is very relevant to tourism, known as a phenomenon that often offers experiences of 'different' and 'extraordinary'. As Deville and Wearing (2013, p. 151) neatly point out:

Tourism must not only operate in a more sustainable manner ... To be transformational, tourism must result in changes that go beyond generating local economic contributions or stimulate donations ... Tourism must stimulate change by provoking a deep questioning of the purpose and meaning of people's life through empathic, engaged, authentic and invited, rather than imposed, encounters with the lives of others.

It is to this view we need to direct our energies when speaking and (re)conceptualizing policies and practices of 'Tourism education in the $21^{\text {st }}$ century'.

\section{References}

Alhadeff-Jones, M. (2012) Transformative learning and the challenges of complexity. In E.W., Taylor, P., Cranton, \& Associates (Eds) Handbook of Transformative Learning: Theory, Research and Practice (pp. 178194). San Francisco: Jossey-Bass.

Anderson, K. (2012) Climate change going beyond dangerous: brutal numbers and tenuous hope. What Next 3 (online) Retrieved from: http://www.whatnext.org/resources/ Publications/Volume-III/Single-articles/ wnv3_andersson_144.pdf

Ateljevic, I. (2009) Transmodernity - remaking our (tourism) world?in Tribe, J. (ed) (2008) Philosophical Issues of Tourism. Elsevier Advanced Social Science Series (pp. 278-300).

Crutzen, P. J. Steffen, W. and McNeil, J. R. (2007) 'The Anthropocene: Are Humans now Overwhelming the Great Forces of Nature?' Ambio 36, pp. 614-621.

Euro RSCG Worldwide (2010) The New Consumer in the Era of Mindful Spending, Know, Vol 8, Summer 2010. (Euro RSCG Worldwide is a leading marketing communications company and the world's largest advertising agency by global brands).

Deville, A. \& Wearing, S. (2013) WWOOFing tourism: Beaten tracks and transformational paths. . In Y. Reisinger (Ed.) Transformational tourism: tourist perspectives (pp. 151-168). Oxfordshire: CABI.

Florida, R. (2010) The Great Reset: How New Ways of Living and Working Drive PostCrash Prosperity. Random House Canada.

The Futures Company (2010) A Darwinian Gale and the Era of Consequences. A White paper published by the Futures Company (a leading global trends and futures research and consultancy business with offices in London, New York, Chapel Hill, NC, Mumbai and Delhi).

Ghisi, L. M. (2008) The Knowledge Society: A Breakthrough Towards Genuine Sustainability. Cochin, India: Arunachala Press. 
Harman, W. (1998) Global Mind Change: Promise of the $21^{\text {st }}$ century.

Haus der Kulturen der Welt (HKW) (2014) The Anthropocene Project.Berlin, 20132014.http://www.hkw.de/en/programm/ projekte/2014/anthropozaen/anthropozaen_2013_2014.php

Inglehart, R. and Norris, P. (2004) Sacred and Secular: Religion and Politics Worldwide. New York: Cambridge University Press.

Klein, N. (2014) This Changes Everything: Capitalism vs. the Climate. London: Penguin Books.

Lovelock, James (2014)A Rough Ride to the Future. London: Penguin Books.

Lovelock, James (2009) The Vanishing Face of Gaia: A Final Warning: Enjoy It While You Can. London: Penguin Books.

Lyon, C. R. (2002) Trigger Event Meets Culture Shock: Linking the Literature of Transformative Learning Theory and CrossCultural Adaptation. Paper presented at the Annual Meeting of the Adult Education Research Conference. North Carolina State University, May 24-26, 2002.

McIntosh, A., Zahra, A. (2007). A cultural encounter through volunteer tourism: Towards the ideals of sustainable tourism. Journal of Sustainable Tourism. 15(5), 541-556.

Mezirow, J. (1996) Contemporary paradigms of learning.Adult Education Quarterly.46:158-172.

Mezirow, J. (2012) Learning to think like an adult: Core concepts of transformational learning theory. In E.W. Taylor, P. Cranton, \& Associates (Eds.). The handbook of transformative learning: Theory, research, and practice(pp. 73-95). San Francisco: John Wiley and Sons.

OECD (2013) Health at a Glance 2013. Paris: OECD.

Ogilvy and Mather (2010) Eyes Wide Open, Wallet Half Shut. New York: Ogilvy and
Mather (an international advertising, marketing and public relations agency based in NY; it operates 450 offices in 161 cities of 120 countries worldwide).

O'Sullivan, E. (2012). Deep transformations: Forging a planetary worldview. In Taylor, E.W., Cranton, P. \& Associates (Eds.) The handbook of transformative learning: Theory, research, and practice.(Pp. 162-177) San Francisco: John Wiley and Sons.

Porter, M. and Mark, K. (2011) Creating Shared Value, Harvard Business Review, Jan-Feb, pp. 62-77.

Ray, P. (1996) 'The Rise of Integral Culture', Noetic Sciences Review, no. 37, pp. 4-16.

Ray, H. P. and Anderson, S. R. (2000) The Cultural Creatives: How 50 Million People Are Changing the World. New York: Harmony Books.

Resilience Alliance. (2009) 'Planetary Boundaries: Exploring the Safe Operating Space for Humanity.' Ecology and Society 14 (2), 32. (Rockström, J., W. Steffen, K. Noone, Å. Persson, F. S. Chapin, III, E. Lambin, T. M. Lenton, M. Scheffer, C. Folke, H. Schellnhuber, B. Nykvist, C. A. De Wit, T. Hughes, S. van der Leeuw, H. Rodhe, S. Sörlin, P. K. Snyder, R. Costanza, U. Svedin, M. Falkenmark, L. Karlberg, R. W. Corell, V. J. Fabry, J. Hansen, B. Walker, D. Liverman, K. Richardson, P. Crutzen, and J. Foley).

Reisinger, Y. (2013) (Ed) Transformational Tourism: Tourist Perspective. Wallingford: CABI.

Senge, P, Sharmer, O. Jaworski, J. and Flowers, B. (2004) Presence: Human Purpose and the Field of the Future. SOL Cambridge.

Sharmer, O. and Katrin K, (2013) Leading from the Emerging Future: From Ego-system to Eco-system Economies. ReadHowYouWant.com.

Shiva, V. (2012) Making Peace with the Earth: Beyond Resource, Land and Food Wars. Delhi: Women Unlimited. 